\title{
FINANCIACIÓN DE PARTIDOS POLÍTICOS Y TRANSPARENCIA: CRÓNICA DE UNA RESISTENCIA*
}

\author{
Vicente A. Sanjurjo Rivo**
}

Resumen: La regulación legislativa de los partidos políticos y, por tanto, también de sus fuentes de financiación, ofrece la singularidad de que son los propios partidos que ocupan el poder legislativo del Estado los que, en última instancia, legislan sobre sí mismos. Por ello los partidos, conscientes de su necesidad de grandes recursos económicos para afrontar sus ingentes gastos, al regular sus fuentes de financiación privada, dejan abiertas posibles vías de financiación que les permita satisfacerlos, sin perjuicio de que simultáneamente se pueda constatar su indudable esfuerzo por regular restrictivamente esas mismas fuentes

Recibido: diciembre 2017. Aceptado: junio 2018

* Este trabajo se enmarca en el Proyecto de Investigación DER2015-71176-R, financiado por el Ministerio de Economía y Competitividad y cofinanciado por el Fondo Europeo de Desarrollo Regional (FEDER) correspondiente al marco financiero plurianual 2014-2020.

** Profesor Contratado Doctor de Derecho Constitucional. ORCID ID: 00000003-3087-967X

Departamento de Derecho Público y Teoría del Estado. Facultad de Derecho de la Universidad de Santiago de Compostela. Avda. Ángel Echeverri, S/N. Campus Vida, CP. 15785, Santiago de Compostela. Email: va.sanjurjo@ usc.es 
de financiación. Y esa doble condición de legislador y objeto de la legislación que aúnan los partidos, tal vez sea una de las posibles causas que a su vez explique el limitado impacto que sobre ellos ha tenido la regulación legislativa en materia de transparencia.

Palabras clave: Financiación de partidos; transparencia; corrupción; donaciones; préstamos bancarios; fundaciones y entidades vinculadas a los partidos.

\title{
FINANCING OF POLITICAL PARTIES AND TRANSPARENCY: CHRONICLE OF A RESISTANCE
}

\begin{abstract}
The legislative regulation of political parties and, therefore, also of their sources of funding, offers the particularity that the parties are who occupy the legislative power of the State and, in the end, legislate on themselves. For this reason, the parties, aware of their need for large economic resources to meet their huge expenses, by regulating their sources of private financing, leave open possible avenues of financing that will allow them to meet that expenses, without prejudice to their undoubted effort to regulate restrictively those same sources of financing. And that double status of legislator and object of the legislation that brings together the parties, is perhaps one of the possible causes that also explains the limited impact that the legislative regulation on transparency has had on them.
\end{abstract}

Keywords: political parties financing; transparency; corruption; donations; loans; foundations and associations linked to the parties.

\section{La dificultad de alterar el statu quo cuando la legislación tiene por objeto al legislador}

La Constitución española (en lo sucesivo CE) remite al legislador el desarrollo y concreción de los elementos esenciales del funcionamiento y estructura interna de los partidos políticos (art. $6 \mathrm{CE}$ ), lo que naturalmente incluye sus fuentes de financiación. Como es sabido, los partidos políticos son asociaciones privadas que ejercen funciones públicas; y no cualquier tipo de funciones públicas, sino unas - expresar el pluralismo político, concurrir a la formación y manifestación de la voluntad popular, facilitar la participación política- imprescindibles para el 
funcionamiento del Estado democrático ${ }^{1}$. Su condición de elementos indispensables para el desarrollo de la vida democrática explica que el constituyente hubiese establecido un límite al poder de autoorganización de los partidos, al exigir expresamente que su estructura interna y funcionamiento debieran ser democráticos (art. $6 \mathrm{CE}$ ), y justifica también un elevado grado de intervención del legislador que, al regularlos, debe garantizar los principios de libertad, justicia, igualdad y pluralismo político $(\text { art. 1.1 CE) })^{2}$.

1 Como tantas otras veces, resulta aquí inevitable acudir al célebre jurista austríaco Hans Kelsen quien, con toda rotundidad, ya señalara en el primer tercio del pasado siglo que la «democracia moderna descansa, puede decirse, sobre los partidos políticos, cuya significación crece con el fortalecimiento progresivo del principio democrático. [...] La democracia, necesaria e inevitablemente requiere un Estado de partidos». [KELSEN, H., Esencia y valor de la democracia, trad. Rafael Luengo Tapia y Luis Legaz y Lacambra, Labor, Barcelona-Buenos Aires, 1934, pp. 35-37 (cursivas en el original)].

2 Los partidos políticos, además, tras el correspondiente y debido proceso electoral, ocupan instituciones básicas del Estado (dejamos ahora a un lado la cuestión de su ocupación patológica o colonización), que los somete también a los requerimientos constitucionales y estatutarios del buen gobierno y de la buena administración. Aunque la CE no recoge expresamente tales requerimientos, se extraen sin embargo sin demasiadas dificultades de su articulado: arts. 9.1 (sujeción de los poderes públicos a la Constitución y al resto del ordenamiento jurídico); 9.3 (principios de legalidad, seguridad jurídica, responsabilidad e interdicción de la arbitrariedad de los poderes públicos); 31.2 (principios de equidad, eficiencia y economía en el gasto público); 97 (ejercicio por el Gobierno de la función ejecutiva y la potestad reglamentaria de acuerdo con la Constitución y las leyes); 103.1 (principios de objetividad, eficacia, sometimiento a la ley y al Derecho en la actuación de la Administración Pública), o 106.1 (control jurisdiccional de la potestad reglamentaria y la legalidad de la actuación administrativa). En cambio, sí se prevén expresamente en las últimas reformas estatutarias, tal y como hace, por ejemplo, el artículo 30 del Estatuto de autonomía de Cataluña (derechos de acceso a los servicios públicos y a una buena administración), o el artículo 31 del Estatuto de autonomía de Andalucía (derecho a una buena administración). Vid. RUIZ-RICO RUIZ, G. J., "El derecho a una buena administración. Dimensiones constitucional y estatutaria", El derecho a una buena administración y la ética pública, Carmen María Ávila Rodríguez y Francisco J. Gutiérrez Rodríguez, (coord.), Tirant lo Blanch, 2011, pp. 55-76. 
Sin embargo, en este caso se produce una circunstancia singular: la regulación legislativa del régimen jurídico de los partidos políticos en general, o de sus fuentes de financiación o régimen de transparencia en particular, se lleva a cabo en las Cortes Generales mediante el acuerdo o pacto entre las distintas estructuras orgánicas de las Cámaras - los grupos parlamentarios - integradas a su vez por los propios partidos políticos. Es decir, se produce en este caso una coincidencia entre lo legislado y el legislador. La regulación legislativa sobre partidos políticos es en realidad una autorregulación: son los distintos partidos con representación parlamentaria los que se dan a sí mismos su régimen jurídico, naturalmente dentro del muy amplio y general marco constitucional. Y, además, en este caso no entra en juego la dialéctica gobierno-oposición, que podría poner en funcionamiento un cierto juego de contrapesos (checks and balances en sentido laxo), sino otra distinta, la protagonizada por el eje partidos con fuerte implantación (mayoritarios) frente a aquellos otros con menor implantación o incluso con implantación residual (minoritarios). Habría pues en este caso una colusión de intereses de los grandes partidos atraídos por el fin compartido de conservar su posición dominante en el sistema de partidos ${ }^{3}$. Esta suerte de cartelización $n^{4}$ de la competencia partidista, y la circunstancia de que además los integrantes de ese hipotético cártel, según se acaba de señalar, estén en condiciones de establecer los distintos aspectos del régimen jurídico que atañe a los competidores (los partidos políticos) y al mercado (electoral) en que compiten, vendría a explicar que cualquier cambio o mo-

3 Es la misma confluencia de intereses que explica la resistencia de esos mismos partidos a modificar la legislación electoral (Ley Orgánica 5/1985, de 19 de junio, del Régimen Electoral General que, a su vez, revalidaba sustancialmente el diseño del régimen electoral llevado a cabo en el Real Decreto-ley 20/1977, de 18 de marzo, sobre Normas Electorales); o la que, desde otra perspectiva, permite a esos mismos partidos colonizar instituciones y órganos del Estado.

4 KATZ, R. S. y MAIR, P., "El partido cartel: La transformación de los modelos de partidos y de la democracia de partidos", Zona abierta, núm. 108-109 (2004): 9-42. 
dificación de ese régimen jurídico debe ser necesariamente un cambio controlado, que no altere el statu quo, o al menos que no lo altere sustancialmente, de suerte que se pueda cronificar su posición prevalente o hegemónica o bien que ésta no se vea comprometida; y sobre esta clave deben entenderse o interpretarse las modificaciones que en materia de financiación y transparencia se exponen en las páginas que siguen.

\section{Las sucesivas reformas legislativas de la financiación de los partidos o "el complejo de Penélope"}

Una buena muestra de esa resistencia de los partidos - mayor cuanto más grandes estos sean o más implantación electoral tengan - a los cambios profundos, y en lo que ahora interesa en materia de financiación, es la constatación de la ausencia de una decidida e inequívoca voluntad política de las élites directivas de esos mismos partidos para establecer eficaces mecanismos de autocontrol en la estructura organizativa interna de los partidos, al amparo del poder de autoorganización que le concede la CE (art. 6). Bien al contrario, las posibles carencias legislativas han sido utilizadas torticeramente por los propios partidos «para generar mecanismos clientelares con agentes sociales y económicos de la sociedad, facilitando de este modo a las formaciones políticas recursos económicos irregulares y no sometidos a fiscalización pública» ${ }^{5}$.

El mantenimiento en sus rasgos esenciales del modelo de financiación de los partidos políticos constituye un buen reflejo de esa renuencia al cambio por parte de los mismos a la que nos venimos refiriendo. Desde sus orígenes, que se remontan al período preconstitucional ${ }^{6}$, hasta el presente, las distintas leyes

5 RUIZ-RICO RUIZ, G. J., "El control sobre la financiación de los partidos políticos: un desafío permanente para el legislador", Teoría y Realidad Constitucional, núm. 35 (2015), p. 307.

6 El ya mencionado Real Decreto-ley 20/1977, de 18 de marzo, sobre Normas Electorales, que preveía un sistema de subvención estatal de los gastos 
que dieron en regular la financiación de los partidos ${ }^{7}$ lo hicieron a partir de un contumaz sostenimiento de ese modelo, asentado sobre la base de la preponderancia de la financiación pública ${ }^{8}$ (haciendo aquí abstracción de la financiación irregular ${ }^{9}$ ), lo cual,

electorales (art. 44), y la Ley 54/1978, de 4 de diciembre, de Partidos Políticos, que establecía una asignación a los partidos políticos con cargo a los Presupuestos Generales del Estado por sus gastos de funcionamiento (art. 6)

7 Desde la LO 5/1985, de 19 de junio, del Régimen Electoral General (LOREG), hasta la reciente LO 3/2015, de 30 de marzo, de control de la actividad económico-financiera de los Partidos Políticos, pasando por la LO 3/1987, de 2 de julio, sobre la Financiación de los Partidos Políticos, la LO 8/2007, de 4 de julio, sobre financiación de los partidos políticos, y su reforma mediante la LO 5/2012, de 22 de octubre.

8 El criterio de reparto de los distintos tipos de subvenciones (para gastos electorales y ordinarios, seguridad, de grupos parlamentarios e institucionales) beneficia sin duda alguna a los grandes partidos con representación parlamentaria $\mathrm{y}$, por extensión, propicia la preservación del statu quo. (Cfr. PAJARES MONTOLÍO, E. J., La financiación de las elecciones, 1 ed., Congreso de los Diputados, Madrid, 1998, pp. 224 y ss.). Ello naturalmente dotó al sistema de partidos de una gran estabilidad, lo que empíricamente se puede comprobar al constatar el carácter prácticamente invariable de nuestro mapa de partidos desde finales de la década de los ochenta, sin ocasionar, no obstante, su total petrificación, pues, con todo, no impidió, tras la reciente e intensa crisis económica e institucional, la aparición de nuevas fuerzas políticas. Ciertamente, el establecimiento de la barrera de la obtención de representación parlamentaria para ser beneficiario de tales subvenciones supone la exclusión del reparto de aquellas fuerzas políticas con un cierto apoyo social, o incluso con un apoyo social significativo, pero que carecen de representación parlamentaria; posibilidad, por otra parte, nada desdeñable en un sistema electoral como el nuestro con un sesgo mayoritario en la mayoría de sus circunscripciones electorales. Y, a su vez, el doble criterio de reparto de la financiación pública entre las distintas fuerzas políticas que hubiesen obtenido representación parlamentaria en función del número de escaños y el número de votos por ellas obtenidos, favorece claramente a los partidos mayoritarios.

9 En este punto, sin embargo, no debe perderse de vista que la financiación pública no viene a suplir sino a acrecer las eventuales fuentes irregulares de financiación de los partidos, a las que, por lo demás, éstos acuden con avidez para afrontar sus crecientes gastos, en especial, los electorales. Cfr. PASQUINO, G., "Contro il finaziamento pubblico di questi partiti", Degenerazioni dei partiti e riforme istituzionali, Laterza, Roma, 1982, pp. 45-73. 
en los primeros años de andadura democrática perseguía el necesario objetivo de consolidación de unas estructuras partidistas por entonces muy débiles ${ }^{10}$, sin excluir la financiación privada, «basada más en los créditos bancarios que en las donaciones y caracterizada sobre todo por su opacidad» ${ }^{11}$.

A tenor, como se acaba de apuntar, que el modelo de financiación pública ha permanecido inalterado, analizaremos a continuación los cambios y modificaciones que el legislador, en cambio, en una suerte de Penélope que desteje de noche lo que teje de día, sí ha introducido en lo relativo a las fuentes de financiación privada de las fuerzas políticas.

\subsection{De las restricciones a las donaciones a la laxitud con las aportaciones a las fundaciones y entidades vincula- das a los partidos}

Las donaciones privadas a los partidos políticos son aportaciones en dinero o en especie que éstos pueden recibir, irrevocables y de carácter no finalista. A pesar de su naturaleza no finalista y su carácter irrevocable, las donaciones privadas representan un instrumento de financiación que potencialmente podría poner en riesgo la autonomía de los partidos, que podrían quedar excesivamente expuestos a los intereses y preferencias de grandes donantes.

Por ello, como tendremos ocasión de comprobar a continuación, el legislador ha hecho un esfuerzo progresivo por limitar o restringir su régimen jurídico, tanto en lo que se refiere a los sujetos activos legitimados para efectuar este tipo de donaciones, a su cuantía, como al perfeccionamiento de su sistema de fiscalización y régimen sancionador.

10 Vid. BLANCO VALDÉS, R. L., "La caída de los dioses: de los problemas de los partidos a los partidos como problemas", Teoría y Realidad Constitucional, núm. 35 (2015), pp. 152-154.

11 SÁNCHEZ MUÑOZ, Ó, "La insuficiente reforma de la financiación de los partidos: la necesidad de un cambio de modelo", Revista española de derecho constitucional, 35, núm. 104 (2015), p. 52. 
Sin duda, ha sido en el ámbito de los potenciales donantes a los partidos políticos en el que el legislador ha puesto un mayor y más decidido empeño restrictivo, en un afán por ir progresivamente estrechando el círculo de los posibles donantes. Siguiendo esta senda la Ley Orgánica 8/2007, de 4 de julio, sobre financiación de los partidos políticos (en adelante LO 8/2007), había previsto la prohibición de que los partidos políticos fuesen donatarios, directa o indirectamente, de organismos, entidades o empresas públicas [art. 4.2 b)]; así como también de empresas privadas que, «mediante contrato vigente, presten servicios o realicen obras para las Administraciones Públicas, organismos públicos o empresas de capital mayoritariamente público» [art. $4.2 \mathrm{c})]^{12}$. Con la reforma introducida por la LO 5/2012 se añade la prohibición de que los partidos puedan resultar beneficiarios de donaciones de fundaciones privadas, asociaciones $\mathrm{u}$ otras entidades que, a su vez, reciban subvenciones de las Administraciones Públicas, o cuyo presupuesto, en todo o en parte, esté integrado por aportaciones de dichas Administraciones ${ }^{13}$.

Con independencia de que alguna de estas prohibiciones presente evidentes deficiencias, como aquélla que se circunscribe a donaciones procedentes de empresas con contratos de obra o servicios en vigor con las Administraciones Públicas sin extender, por tanto, tal prohibición a las eventuales donaciones de empresas incursas en procedimientos de selección de adjudicatarios, y sin prever tampoco un período de carencia al que se extienda dicha prohibición tras la terminación o extinción del

12 En la redacción dada a este precepto por la Ley Orgánica 5/2012, de 22 de octubre, de reforma de la Ley Orgánica 8/2007, de 4 de julio, sobre financiación de los partidos políticos (en lo sucesivo LO 5/2012), se extendió esta prohibición a las donaciones procedentes de empresas pertenecientes al mismo grupo de aquéllas que prestan servicios o son adjudicatarias de obras para las Administraciones Públicas, o de empresas participadas mayoritariamente por éstas, así como también de sus fundaciones. (art. 1 LO 5/2012).

13 Adición de la letra d) en el artículo 4.2 de la LO 8/2007 en virtud de lo dispuesto en el art. 1 de la LO 5/2012. 
correspondiente contrato de obra o servicio; lo cierto es que de todas ellas se deja traslucir el intento - fallido si acudimos a los hechos ${ }^{14}$ — de evitar, o aminorar al menos, las consecuencias indeseadas derivadas de la contrastada capacidad de ocupación y control por los partidos políticos de los órganos del Estado y de su administración. Tal vez por ello la Ley Orgánica 3/2015, de 30 de marzo, de control de la actividad económico-financiera de los Partidos Políticos (en adelante LO 3/2015), en la nueva redacción dada al artículo 5 de la LO 8/2007, introduce la prohibición genérica de que los partidos políticos puedan aceptar o recibir donaciones procedentes de personas jurídicas y de entes sin personalidad jurídica ${ }^{15}$.

En esa dirección de limitar los posibles donantes a fin de evitar colusiones de intereses que se pudiesen traducir en vías indirectas de financiación, o incluso - y sobre todo- en mecanismos de financiación irregular, y de ofrecer igualmente un marco de publicidad (restringida) sobre los mismos, se inscribe la prohibición general y no sujeta a excepción alguna ${ }^{16}$ de las donaciones anónimas introducida por la LO 8/2007 (art. 5).

14 No es necesario recordar aquí la gran cantidad y variedad de casos de corrupción ligados a la financiación irregular de los partidos que han salpicado - y siguen salpicando- la vida política de nuestro país. A título simplemente ilustrativo, y sin ánimo exhaustivo, pueden mencionarse los casos Gürtell, Malaya, Palma Arena, Pretoria, Campeón, Millet, Pokemon, Bárcenas o Púnica, entre otros.

15 Artículo 5 c) de la LO 8/2007 en virtud de su nueva redacción en los términos previstos en el artículo 1.4 de la LO 3/2015. No obstante, el artículo 129 de la Ley Orgánica 5/1985, de 19 de junio, del Régimen Electoral General (LOREG), faculta a las personas jurídicas a hacer aportaciones de hasta un máximo de 10.000 euros en las cuentas abiertas por los partidos a fin de recaudar fondos para hacer frente a los gastos electorales en las correspondientes elecciones; precepto que, en atención al criterio de la especialidad, rige y no puede entenderse implícitamente derogado por el señalado artículo 5 c) de la LO 8/2007, según la redacción dada por la LO $3 / 2015$.

16 No obstante, si la cantidad abonada al partido fuese inferior a 300 euros y proviniese de actividades propias del partido o de sus propiedades no sería necesaria la identificación del transmitente (art. 6 LO 8/2007). 
Conviene recordar que hasta entonces las donaciones anónimas contaban con plena cobertura legal, con el único límite de que la cuantía total de este tipo de donaciones recibidas en un ejercicio económico anual por un partido político no podría sobrepasar el 5 por 100 de la cantidad asignada a ese mismo partido en los Presupuestos Generales del Estado en concepto de subvención para atender sus gastos de funcionamiento ordinario [art. 4.3 a) de la Ley Orgánica 3/1987, de 2 de julio, sobre financiación de los partidos políticos]; si bien es cierto que la superación de ese límite no comportaba el establecimiento de sanción alguna por el Tribunal de Cuentas, debido al vacío legal respecto al régimen sancionador aplicable. No obstante, esta proscripción de las donaciones anónimas no se traduce en un deber de los partidos de publicar sus donantes, sino únicamente en un deber de identificarlos (art. 14. 5 LO 8/2007) a fin de que el Tribunal de Cuentas pueda ejercer su función fiscalizadora ${ }^{17}$.

Igualmente, se ha experimentado una notable reducción en la cuantía máxima legalmente permitida de las donaciones privadas. Así, el límite de los 100.000 euros anuales por donante establecido en la LO 8/2007 (art. 5) se ve reducido a la mitad

17 La cuestión de la prohibición de las donaciones anónimas no dejaba de tener aspectos vidriosos como, por ejemplo, sus posibles consecuencias en un entorno de presión terrorista con cierto respaldo político y social, como era el caso por entonces del País Vasco. En cuanto al conflicto de derechos que se suscita con la publicación de los donantes, que afecta, por una parte, a los derechos de éstos a la libertad ideológica (art. $16 \mathrm{CE}$ ), y al derecho a la intimidad y a la protección de datos personales (art. $18 \mathrm{CE}$ ), y, por la otra, al derecho de acceso de los ciudadanos a una información que puede ser relevante para la formación de su voluntad política y para el adecuado ejercicio de su derecho de participación en los asuntos públicos a través del ejercicio del derecho de sufragio en elecciones periódicas (art. 23.1 CE); y la circunstancia de que un elemento determinante para dirimir tal conflicto pueda ser la propia cuantía de las donaciones, de manera que cuanto menor sea ésta más se debilita el derecho de acceso a esa información por parte de los ciudadanos y simultáneamente más se refuerza el derecho de los donantes a preservar su intimidad, y viceversa, puede leerse SÁNCHEZ MUÑOZ, "La insuficiente reforma de la financiación de los partidos: la necesidad de un cambio de modelo", pp. 79-80, cit. en nota núm. 11. 
(50.000 euros anuales por donante) por la LO $3 / 2015^{18}$. Aunque también aquí se deja una vía abierta al exonerar de dicho límite a las donaciones en especie de bienes inmuebles (art. 5 LO 8/2007). A su vez, se aprecia un esfuerzo por mejorar y perfeccionar el sistema de fiscalización y control de las donaciones, al introducir la obligación para los partidos políticos de notificar al Tribunal de Cuentas las donaciones recibidas superiores a 50.000 euros (a 25.000 euros tras el establecimiento en 50.000 euros la cuantía máxima anual de las donaciones por persona ${ }^{19}$ ) y las de bienes inmuebles ${ }^{20}$; así como también el régimen sancionador, al atribuir al Tribunal de Cuentas la vigilancia de que las sanciones se hacen efectivas antes del libramiento de la correspondiente subvención ${ }^{21}$.

Sin embargo, este incontestable denuedo del legislador por ir paulatinamente acotando y reduciendo los potenciales donantes de los partidos políticos, desterrando el anonimato de las donaciones y sustituyéndolo por un marco (limitado) de publicidad, al tiempo que reducía sustancialmente la cuantía máxima anual de las donaciones por persona y partido y mejoraba de forma notable los instrumentos de control y el régimen sancionador, contrasta con la llamativa — por no decir escandalosa-

18 Artículo 5 b) de la LO 8/2007 en virtud de su nueva redacción en los términos previstos en el artículo 1.4 de la LO 3/2015.

19 Artículo 5.2 de la LO 8/2007 según la nueva redacción dada por virtud del artículo 1.4 de la LO 3/2015.

20 Artículo 5.2 de la LO 8/2007 según la nueva redacción dada por virtud del artículo 3 de la LO 5/2012.

21 Artículo 17.2 de la LO 8/2007 según la nueva redacción dada por virtud del artículo 7 de la LO 5/2012, y que se mantiene — aunque no literalmenteen el vigente artículo 17 bis. 4 de la LO 8/2007, según la redacción dada por el artículo 1.14 de la LO 3/2015 que, por lo demás, viene a desarrollar y pormenorizar el régimen sancionador en coherencia con el sistema de infracciones previsto en el artículo 17. Con relación a la potestad sancionadora del Tribunal de Cuentas en los ámbitos de la financiación ordinaria y la financiación electoral de los partidos, vid. DELGADO DEL RINCÓN, L. E., "El control económico-financiero de los partidos políticos por el Tribunal de Cuentas: su potestad sancionadora", Revista de derecho político, núm. 97 (2016): 49-88. 
relajación del régimen jurídico aplicable a las aportaciones a las fundaciones y entidades vinculadas a los partidos.

En efecto, mientras, como hemos tenido ocasión de comprobar, la LO 8/2007 excluía de entre los posibles donantes de los partidos políticos a aquellas empresas privadas que, con contrato en vigor, prestasen servicios o realizasen obras para las Administraciones Públicas, organismos públicos o empresas de capital mayoritariamente público; expresamente las admitía, sin embargo, como eventuales donantes de las fundaciones y asociaciones vinculadas a los partidos (Disposición adicional 7 $7^{\mathrm{a}}{ }^{22}$. Y no dejaron de serlo - potenciales donantes - cuando, con la reforma introducida por la LO 3/2015, se prohibieron las donaciones procedentes de personas jurídicas y de entes sin personalidad jurídica a partidos políticos, pero no a sus fundaciones y entidades vinculadas ${ }^{23}$.

De modo análogo, el camino regulatorio de progresiva disminución de la cuantía máxima anual por persona de las donaciones a los partidos políticos (de los 100.000 euros establecidos por la LO 8/2007 a los 50.000 euros fijados por la LO 3/2015), ha sido justamente el inverso al recorrido con relación a las fundaciones y entidades vinculadas a los partidos: del límite de los 150.000 euros estipulado para ellas por la disposición adicional $7^{\text {a }}$ de la LO 8/2007 (un 50 por ciento superior al que la misma ley preveía para los partidos), a la supresión de cualquier

22 Esta mayor permisividad de la LO 8/2007 con relación a los posibles donantes de las fundaciones respecto a los de los partidos políticos puede explicar, al menos en buena medida, que las aportaciones recibidas por las fundaciones vinculadas a los partidos prácticamente se triplicase entre los ejercicios económicos de 2007 y 2008: 3,2 millones de euros correspondientes al ejercicio 2007 frente a los 9,1 millones de euros imputables al ejercicio 2008. (Los datos están tomados de SÁNCHEZ MUÑOZ, "La insuficiente reforma de la financiación de los partidos: la necesidad de un cambio de modelo", p. 60, cit. en nota núm. 11).

23 Disposición adicional $7^{\mathrm{a}}$. 4 de la LO 8/2007 según la redacción dada por el artículo 1.16 de la LO 3/2015. 
límite introducida por la LO 5/2012 $2^{24}$ y mantenida por la LO $3 / 2015^{25}$, con la única cautela de que aquellas donaciones a fundaciones o entidades vinculadas a partidos superiores a 120.000 euros deberán ser formalizadas en documento público (Disposición adicional $7^{\mathrm{a}} .4$ de la LO 8/2007) ${ }^{26}$.

A todo ello habría que añadir la práctica común y creciente de las fundaciones de celebrar convenios de colaboración con personas jurídico-privadas, e incluso públicas, en los que, con frecuencia, las contraprestaciones ofrecidas por la fundación o entidad vinculada a cambio de la correspondiente retribución dineraria, o no están bien definidas, o son tan genéricas que en realidad se confunden con la actividad propia de la fundación o entidad en cuestión. No parece muy aventurado suponer que detrás de la firma de muchos de estos convenios se encierran en realidad donaciones encubiertas. Y así lo ha entendido el Tribunal de Cuentas, que en su primer informe sobre la contabilidad ordinaria de los partidos correspondiente al ejercicio de 2007 interpretó que este tipo de aportaciones realizadas mediante convenios de colaboración deberían de tener la consideración de donaciones ${ }^{27}$.

24 Disposición adicional $7^{\mathrm{a}} .3$ a) de la LO 8/2007 según la redacción dada por el artículo 10 de la LO 5/2012.

25 Disposición adicional 7 $7^{\mathrm{a}}$. 4 de la LO 8/2007 según la redacción dada por el artículo 1.16 de la LO 3/2015.

26 Significativamente, las donaciones a estas entidades vinculadas a los partidos políticos, como también, por cierto, las condonaciones parciales o totales de deudas a los partidos por las entidades de crédito que abordaremos a continuación, quedan excluidas del objeto material del delito de financiación ilegal de partidos políticos previsto en el artículo 304 bis del Código Penal (CP); y, a su vez, estas fundaciones o entidades vinculadas quedan igualmente al margen de la relación de posibles sujetos activos del delito de financiación ilegal previsto en dicho artículo. (Vid. PUENTE ABA, L. M., El delito de financiación ilegal de partidos políticos, Tirant lo Blanch, Valencia, 2017, pp. 85-86, 88 y 95-99).

27 Según el Tribunal de Cuentas los convenios de colaboración se sustentan en un ánimo de liberalidad cuyo fin es el desarrollo de los fines propios de la fundación y, en consecuencia, las aportaciones que ésta reciba a tal fin deben de tener la consideración de donaciones. Se apoya el Tribunal 
Sin embargo, el legislador — confirmando la hipótesis aquí formulada de las disfuncionalidades originadas cuando la legislación tiene por objeto al legislador- lejos de seguir la línea interpretativa del Tribunal de Cuentas, y para no dejar lugar a dudas, dispuso, mediante la introducción por la LO 5/2012 de un nuevo apartado en la Disposición adicional $7^{\text {a }}$ de la LO 8/2007, que en ningún caso tendrán la consideración de donaciones «las entregas monetarias o patrimoniales llevadas a cabo por una persona física o jurídica para financiar una actividad o un proyecto concreto de la fundación o asociación, en cuanto tal actividad o

en el artículo 25 de la Ley 49/2002, de régimen fiscal de las entidades sin fines lucrativos y de los incentivos fiscales al mecenazgo, en el que se establece que «se entenderá por convenio de colaboración empresarial aquél por el cual las entidades, a cambio de una ayuda económica para la realización de las actividades que efectúen en cumplimiento del objeto o finalidad específica, se comprometen a difundir, por cualquier medio, la participación del colaborador en dichas actividades, difusión que no constituye una prestación de servicios»; y en la Resolución de la Dirección General de Tributos de 9 de marzo de 1999 que, al analizar la diferencia entre los convenios de colaboración y el contrato de patrocinio publicitario, señala que «los ingresos procedentes de los Convenios de Colaboración no se refieren al pago de un precio por la prestación de un servicio, sino a la entrega de dinero, con ánimo de liberalidad [...]. La ayuda económica percibida se concede de forma esencialmente gratuita, sin que el compromiso de difusión de la identidad del colaborador pueda considerarse como constitutivo de ninguna transacción entre la entidad sin fin lucrativo y el colaborador», de manera que esa ayuda económica en ningún caso «puede considerarse como contraprestación directa de servicio alguno». [Cfr. «Informe de fiscalización de los estados contables de los partidos políticos y de las donaciones percibidas por las fundaciones vinculadas orgánicamente, ejercicio 2007», en BOE, 5 de marzo de 2013, núm. 55, en el que el Tribunal de Cuentas reitera la argumentación transcrita en los resultados de fiscalización de las Fundaciones Galiza Sempre; Jaime Vera; Fundación para el Análisis y Estudios Sociales (FAES), e Institut d'Estudis Humanistics Miquel Coll y Alentorn (INEHCA), pp. 17992, 17998, 18006 y 18021-18022 respectivamente, (cursivas nuestras)]. El Tribunal ha mantenido idéntica interpretación en informes posteriores. En este sentido, puede consultarse el «Informe de fiscalización de los estados contables de los partidos políticos y de las donaciones percibidas por las fundaciones vinculadas orgánicamente, ejercicio 2008», BOE, 11 de febrero de 2014, núm. 36, con relación a los resultados de fiscalización de la Fundación 
proyecto se realice como consecuencia de un interés común derivado de las actividades propias del objeto societario o estatutario de ambas entidades $\rangle^{28}$. Por esta vía, en consecuencia, se universalizaban además las fuentes de ingreso, al poder celebrar este tipo de convenios y efectuar las correspondientes aportaciones no sólo empresas privadas, sino también Administraciones públicas, organismos, entidades y empresas públicas, pues no lo excluye la propia Disposición adicional reproducida ${ }^{29}$.

Así las cosas, no es de extrañar que el Grupo de Estados Contra la Corrupción (GRECO) $)^{30}$, en su Segundo Informe de

de Estudios Municipales y Territoriales; la Fundación Galiza Sempre; la Fundación Jaime Vera; la Fundación para el Desarrollo Económico y Social de la Comunidad de Madrid (FUNDESCAM); la Fundación para el Estudio de los Problemas de las Ciudades, y la Fundación Perspectivas de Castilla y León, pp. 11767; 11775; 11782; 11797; 11799, y 11801 respectivamente; y el «Informe de fiscalización de los estados contables de los partidos políticos y de las donaciones percibidas por las fundaciones vinculadas orgánicamente, ejercicios 2009, 2010 y 2011», BOE, 12 de mayo de 2014, núm. 115, con relación a los resultados de fiscalización de las fundaciones Galiza Sempre; Ideas para el Progreso; Fundación para el Análisis y Estudios Sociales (FAES); Fundación para el Estudio de los Problemas de las Ciudades, y Fundación Sabino Arana, pp. 36798; 36804; 36820; 36824, y 36841 respectivamente.

28 Disposición adicional $7^{\mathrm{a}}$. 4 de la LO 8/2007 según la redacción dada por el artículo 10 de la LO 5/2012.

29 De los datos tomados del último informe de que disponemos del Tribunal de Cuentas relativo a la fiscalización de las cuentas de los partidos y de las aportaciones a las fundaciones vinculadas correspondiente al ejercicio de 2013, se desprende que, del total de los 4.779.852,7 euros en concepto de aportaciones realizadas en favor de las fundaciones, 1.419 .002 euros corresponden a convenios de colaboración, lo que representa un $29,68 \%$ del total de las aportaciones recibidas. (Elaboración propia a partir de los datos reflejados en el «Informe de fiscalización de los estados contables de los partidos políticos y de las aportaciones percibidas por las fundaciones y asociaciones vinculadas orgánicamente, ejercicio 2013», BOE, 7 de abril de 2017, núm. 83).

30 El Grupo de Estados Contra la Corrupción (GRECO) es un organismo del Consejo de Europa creado con el objeto de prevenir fenómenos de corrupción. 
Cumplimiento de $2013^{31}$, mostrase sus dudas sobre las posibilidades o vías que la LO 5/2012 abre para desviar dinero hacia las fundaciones y asociaciones vinculadas a los partidos, y señalase que la regulación que introduce esta ley con relación a las posibles fuentes de ingresos de las fundaciones es mucho más amplia y permisiva que la de la legislación anterior ${ }^{32}$; de manera que - concluye - ello podría dar pie a que se utilizasen estas fundaciones como una vía paralela de financiación de los partidos políticos, salvando de este modo las mayores restricciones y el perfeccionamiento de los mecanismos de control y el régimen sancionador que, respecto a la financiación de éstos, introduce la propia ley ${ }^{33}$.

En este punto, al menos, no se puede decir que el legislador español haya estado particularmente atento a las recomendaciones del GRECO, pues la nueva regulación introducida por

31 A fin de abordar en toda su extensión el problema de la corrupción, el GRECO adoptó en 2003 una Recomendación y, a partir de entonces, desarrolló varias rondas de evaluación sobre distintos aspectos de la corrupción incluidos en dicha Recomendación. Pues bien, la tercera ronda de evaluación, que se abrió en 2007, afronta la financiación de los partidos políticos. Dentro de esta ronda se han publicado los siguientes informes: un Informe de Evaluación (28 de mayo de 2009); un Informe de Cumplimiento (12 de abril de 2011); un Segundo Informe de Cumplimiento (11 de julio de 2013), respecto al cual se ha publicado además un Addendum (3 de marzo de 2015) y un segundo Addendum (9 de febrero de 2016).

32 Concretamente señala en su Segundo Informe de Cumplimiento que «GRECO has however misgivings as to the possibilities that the law opens up, by virtue of the applicable exceptions, to funnel "interested" money to political foundations or associations. GRECO notes that the exceptions provided by Law 5/2012 with respect to the permissible sources of income, which a political association/foundation may receive, are much broader than those available under the former law». Third Evaluation Round. Second Compliance Report on Spain. "Incriminations (ETS 173 and 191, GPC 2). Transparency of Party Funding», (11 de julio de 2013), § 38, disponible en https://rm.coe.int/16806c9db2 [último acceso: 2017].

33 En palabras del GRECO: «It would be essential to ensure that political foundations and associations are not used as a parallel avenue for funding routine and campaign activities of political parties in spite of the applicable restrictions and thresholds set by law for the latter». Ibid. $§ 70$. 
la LO 3/2015 no altera sustancialmente nada en lo relativo a las aportaciones recibidas por las fundaciones y asociaciones vinculadas a través de los convenios de colaboración, que continúan sin tener la consideración de donaciones; pueden seguir celebrándose con personas jurídicas públicas y privadas; y únicamente se introduce la reserva de que estas entregas que traen causa de un convenio de colaboración deberán, en cualquier caso, formalizarse en documento público, informar de las mismas al Tribunal de Cuentas en el plazo de tres meses desde su aceptación, y darles publicidad, preferentemente a través de la página web de la fundación o entidad vinculada, si bien no se establece plazo alguno para hacer efectiva esta exigencia ${ }^{34}$. No debe sorprender tampoco ahora que el GRECO en el Addendum al Segundo Informe de Cumplimiento, de 3 de marzo de 2015, al referirse al por entonces proyecto de ley orgánica de control de la actividad económico-financiera de los Partidos Políticos (LO 3/2015, de 30 de marzo, una vez aprobada), reiterase los mismos reparos - la plausible utilización de las fundaciones y entidades vinculadas como vías indirectas de financiación de los partidos ${ }^{35}$ - que ya había planteado en el Segundo Informe de Cumplimiento con relación a la regulación prevista en esta materia por la LO 5/2012; e instase a las autoridades españolas a que adoptasen medidas efectivas destinadas a subsanar estas deficiencias, a fin de restablecer la credibilidad del sistema polí-

34 Disposición adicional $7^{\mathrm{a}}$. 5 de la LO 8/2007 según la redacción dada por el artículo 1.16 de la LO 3/2015. Téngase en cuenta, además, con relación al requisito de publicitar sin sujeción a plazo estas aportaciones procedentes de convenios de colaboración en la web de la fundación o asociación vinculada, que alrededor del 40 por 100 de las mismas no tiene website. Cfr. MARTÍN CAVANNA, J., Los 10 mayores errores sobre transparencia, supervisión y buen gobierno 2014-2015, Fundación Compromiso y Transparencia, Madrid, 2015, p. 20. Disponible en http://ifuturo.org/documentacion/ Los10mayoreserroressobretransparencia.pdf, [último acceso: 2017].

35 Cfr. Third Evaluation Round. Addendum to the Second Compliance Report on Spain. "Incriminations (ETS 173 and 191, GPC 2). Transparency of Party Funding», (3 de marzo de 2015), §§ 34, 56, disponible en https:// rm.coe.int/16806c9db6 [último acceso: 2017]. 
tico español, que había sufrido — a juicio del GRECO — grave merma a tenor de los numerosos casos de corrupción política que habían aflorado en los últimos años ligados a la financiación irregular de los partidos ${ }^{36}$.

De igual modo, y en coherencia con su línea argumental, el GRECO reiteraba en el Segundo Addendum al Segundo Informe de Cumplimiento, de 9 de febrero de 2016, sus temores y recelos respecto a que la regulación relativa a las fundaciones y entidades vinculadas de la ahora ya en vigor LO 3/2015 pudiese ser utilizada de forma espuria como un instrumento de financiación de los partidos políticos, los cuales, a la vez que podrían encontrar en sus fundaciones una vía expedita para obtener financiación ${ }^{37}$, podrían vadear las más exigentes y restrictivas condiciones de financiación que a ellos sí le imponía la nueva legislación ${ }^{38}$. En concreto - apuntaba el GRECO en su Segundo Addendum al Segundo Informe de Cumplimiento-, aunque la LO 3/2015 proscribe las donaciones de personas jurídicas a partidos políticos, las permite, en cambio, cuando las hagan en favor de sus fundaciones o asociaciones vinculadas. Además, la nueva cuantía máxima — 50.000 euros — de las donaciones a los partidos por persona física y año fiscal introducida por la nueva ley, no rige para las realizadas en favor de las fundaciones, no sujetas por el contrario a límite alguno. Y, en fin, —señala el

36 "Given the number of scandals regarding irregular party funding that have rocked the Spanish political system in recent years, it is of vital importance for the credibility and effectiveness of such a system that the Spanish authorities take prompt action in this domain and provide for tangible improvements without delay». Ibid. $\S 56$.

37 En este sentido el Informe de la Subcomisión relativa al régimen y la financiación de los partidos políticos, (BOCG, 22 de marzo de 2018, núm. 323 , p. 91), apuntaba la posibilidad de que las fundaciones vinculadas pudiesen realizar aportaciones monetarias a los partidos o satisfacer sus gastos produciéndose un corte en la secuencia de control.

38 Cfr. Third Evaluation Round. Second Addendum to the Second Compliance Report on Spain. "Incriminations (ETS 173 and 191, GPC 2). Transparency of Party Funding», (9 de febrero de 2016), §§ 37, 41 y 65, disponible en https://rm.coe.int/16806cac21 [último acceso: 2017]. 
GRECO - las aportaciones de una persona física o jurídica a una fundación o entidad vinculada a través de un convenio de colaboración no tienen la consideración de donaciones ${ }^{39}$. Seguramente son éstas demasiadas excepciones, demasiadas vías de financiación que se abren - las de las fundaciones y entidades vinculadas-, en una especie de movimiento reflejo, mientras otras se cierran o se restringen - las de los partidos políticos-; demasiadas como para no sospechar, cuando menos, que en esta ocasión el legislador-legislado (los partidos políticos) ha procurado salvaguardar y dejar abierta una puerta trasera que le asegure un caudal de financiación imprescindible para hacer frente a sus cuantiosos gastos ordinarios y electorales.

\subsection{Los préstamos bancarios}

Como ya se ha señalado anteriormente, la significativa financiación pública de los partidos políticos sirvió para apuntalar sus débiles estructuras en el momento en que iniciaba su andadura el régimen constitucional de 1978; sin perjuicio de que esos mismos partidos pudiesen acudir a la financiación privada, cosa que hicieron de forma creciente para hacer frente a sus gastos en progresivo aumento, y señaladamente a través de los créditos contratados con las entidades financieras.

Si hubiese que precisar los rasgos que mejor definen la regulación legal en este ámbito de la financiación de los partidos a través de los créditos bancarios, tal vez los que mejor lo harían serían los de permisividad y opacidad. Tanta ha sido la permisividad, que la LO 8/2007 ni siquiera preveía o estipulaba un límite de endeudamiento de los partidos ${ }^{40}$. A ello habría que

39 Ibid. $\S 40$.

40 Tal vez con ello no se hacía otra cosa más que dar carta de naturaleza a una situación previa que había desbordado el límite de endeudamiento impuesto por la LO 3/1987, en virtud del cual el pago de las amortizaciones anuales de los créditos contratados por los partidos en ningún caso podría superar el 25 por 100 de las subvenciones públicas anuales que hubiesen recibido por gastos ordinarios y por funcionamiento de los grupos parlamentarios (art. 8 de la LO 3/1987, de 2 de julio, sobre financiación de los partidos políticos). 
añadir que, para cubrir el vacío de la LO 3/1987 con relación a los acuerdos de renegociación de la deuda entre los partidos y los bancos, que en no pocas ocasiones además desembocaban en condonaciones totales o parciales de deuda, la nueva LO 8/2007 venía a ofrecer respaldo legal pleno a este tipo de acuerdos (Disposición transitoria segunda). Si se combinan ambas circunstancias - endeudamiento ilimitado y cobertura legal a los acuerdos de renegociación de deuda-, seguramente no será muy difícil imaginar que el escenario que se abrirá ante nosotros será el del sobreendeudamiento ${ }^{41}$ de los partidos políticos y el de una mayor y más comprometida dependencia de éstos respecto a los bancos. Y aquí, una vez más, se puede apreciar ese constante hacer y deshacer, ese tejer y destejer al que venimos haciendo referencia, pues la LO 8/2007, como ya hemos tenido ocasión de comprobar, mientras por un lado reducía sustancialmente los potenciales donantes a los partidos políticos, por el otro en cambio, y como sucedía también con las aportaciones a las fundaciones y entidades vinculadas, era sumamente permisiva con los posibles préstamos concedidos a los partidos particularmente ventajosos respecto a las condiciones generales del mercado, así como con las condonaciones de deuda, lo que constituye en ambos casos supuestos de donaciones encu-

41 Incremento del endeudamiento advertido por el GRECO que, en su Informe de Evaluación, señalaba, utilizando fuentes facilitadas por el Tribunal de Cuentas, que la estimación de la deuda contraída por los partidos políticos ascendía en 2005 a 144.800.000 euros. [Cfr. Tercera Ronda de Evaluación. «Informe de Evaluación sobre Transparencia en la Financiación de Partidos Políticos en España», (28 de mayo de 2009), § 74, disponible en https:// rm.coe.int/16806c9d70, (último acceso: 2017)]. Esta cifra ascendió apreciablemente en los años sucesivos con ligeras oscilaciones de pequeños dientes de sierra, y en 2013 (último ejercicio fiscalizado del que disponemos de datos) el nivel de endeudamiento conjunto de las distintas formaciones políticas representaba un total de 205,7 millones de euros. (Vid. «Informe de fiscalización de los estados contables de los partidos políticos y de las aportaciones percibidas por las fundaciones y asociaciones vinculadas orgánicamente, ejercicio 2013», BOE, 7 de abril de 2017, núm. 83, pp. 27684-27685). 
biertas $^{42}$. O sea, mientras con una mano se reducen las posibles fuentes de financiación de los partidos, con la otra, en cambio, se abre - y mucho - otra u otras posibles vías de financiación.

Por si hubiese alguna duda respecto a que las condonaciones totales o parciales de deuda de los partidos por las entidades de crédito encubrían en realidad donaciones, ha sido el propio legislador el que se ha encargado, consciente o inconscientemente, de despejar cualquier duda al respecto: en primer lugar, al someter a las condonaciones de deuda al mismo límite anual de 100.000 euros que a las donaciones ${ }^{43}$; y después al prohibirlas, del mismo modo y al mismo tiempo que prohibía las donaciones de personas jurídicas a los partidos políticos. ${ }^{44}$

El otro rasgo definidor de la regulación en materia de financiación de los partidos vía crediticia al que antes hacíamos referencia es la opacidad. Opacidad que en buena medida había propiciado la propia legislación, al no regular los términos y condiciones de los préstamos concedidos, tales como el valor máximo de los préstamos, esto es, el establecimiento de un límite al endeudamiento, las entidades de crédito admisibles o las

$42 \mathrm{Y}$ así fue denunciado sin ambages por el GRECO en Third Evaluation Round. Compliance Report on Spain. "Incriminations (ETS 173 and 191, GPC 2). Transparency of Party Funding», (12 de abril de 2011), §59, disponible en https://rm.coe.int/16806c9daf, [último acceso: 2017]. Casi dos años antes, el propio GRECO, en su Informe de Evaluación sobre España, se hacía eco del ilustrativo dato de que en el período que abarca de 1997 a 1999 se estimaba que la deuda cancelada ascendía a un total de 19.100 .000 euros. (Cfr. Tercera Ronda de Evaluación. «Informe de Evaluación sobre Transparencia en la Financiación de Partidos Políticos en España», § 74, cit. en nota núm. 41).

43 Según establecía el nuevo apartado 4 del artículo 4 de la LO 8/2007, de 4 de julio, adicionado en virtud del artículo 2 de la LO 5/2012, de 22 de octubre.

44 Según dispone el artículo 4.4 de la LO 8/2007, de 4 de julio, en virtud de la redacción dada por el artículo 1.3. de la LO 3/2015, de 30 de marzo. Debe tenerse presente que el propio artículo 4.4 de la LO 8/2007 aclara que por condonación de deuda debe entenderse «la cancelación total o parcial del principal del crédito o de los intereses vencidos o la renegociación del tipo de interés por debajo de los aplicados en condiciones de mercado». 
condiciones de pago, entre otros ${ }^{45}$; lo cual, a su vez, ofrecía un marco regulatorio idóneo para eludir — como también lo hacía el relativo a las fundaciones y entidades vinculadas - la cada vez más restrictiva legislación en materia de donaciones privadas a los partidos políticos ${ }^{46}$.

Cierto es, sin embargo, que el legislador ha hecho un importante aunque limitado esfuerzo, como veremos a continuación, en lo concerniente a las garantías de transparencia con relación a las condiciones de los préstamos concedidos a los partidos. Así, la LO 5/2012 disponía que los partidos políticos tendrían que informar al Tribunal de Cuentas y al Banco de España de los acuerdos que alcanzasen con las entidades de crédito respecto de las condiciones de la deuda que hubiesen contraído con ellas ${ }^{47}$; así como también vendrían obligados a hacer públicos, preferentemente a través de su página web, «la cuantía de los créditos que les han sido concedidos, el tipo de entidad concedente y las condonaciones de deuda $\imath^{48}$ correspondientes a un determinado ejercicio, si bien no se preveía plazo alguno para el cumplimiento de esta obligación, ni tampoco sanción alguna para el caso de incumplimiento. Esta carencia, no obstante, fue parcialmente subsanada por la LO 3/2015 que, además de detallar aún más la información que debía ser publicada en la web de los partidos (la cuantía de los créditos pendientes de amortización, la entidad concedente, el importe otorgado, el tipo de interés y el plazo de amortización), establecía un plazo máximo de

45 Laguna que, por cierto, ya había sido advertida por el GRECO en su Informe de Evaluación. (Cfr. Tercera Ronda de Evaluación. «Informe de Evaluación sobre Transparencia en la Financiación de Partidos Políticos en España», § 74 , cit. en nota núm. 41).

46 Y así lo expresó el GRECO en su Segundo Informe de Cumplimiento sobre España. [Cfr. Third Evaluation Round. Second Compliance Report on Spain. "Incriminations (ETS 173 and 191, GPC 2). Transparency of Party Funding», $\S 27-28$, cit. en nota núm. 32].

47 Así lo estipulaba el nuevo apartado 4 del artículo 4 de la LO 8/2007, de 4 de julio, adicionado en virtud del artículo 2 de la LO 5/2012, de 22 de octubre.

48 Nuevo apartado 8 del artículo 14 de la LO 8/2007, de 4 de julio, adicionado en virtud del artículo 4 de la LO 5/2012, de 22 de octubre. 
un mes desde la fecha de envío de las cuentas anuales al Tribunal de Cuentas para hacerlo ${ }^{49}$. Con todo, al no fijarse un límite al endeudamiento, el mayor problema continúa siendo el sobreendeudamiento de los partidos, que quedan en una posición vulnerable y excesivamente expuestos a las entidades financieras, con todos los riesgos en términos de autonomía y fijación de la agenda política que ello podría comportar ${ }^{50}$.

\section{Transparencia y partidos políticos}

Si quisiésemos sintetizar en pocas palabras cuál ha venido siendo hasta ahora la relación entre partidos y transparencia, tal vez una buena manera de hacerlo, o al menos una posible y bastante ajustada a la realidad, sería aludiendo a que esa relación no ha sido demasiado fructífera o, dicho de otro modo, que los partidos no han sido precisamente muy permeables a la transparencia, aunque es indudable también que algún avance se ha producido en este ámbito. Y aquí, una vez más, resulta inevitable volver sobre el principio, retomar aquella idea de que en general nadie es muy proclive o entusiasta de las autolimitaciones, y en esto los partidos políticos no son tampoco una excepción cuando intervienen como partidos-legisladores que legislan sobre sí mismos.

A tenor de las categorías utilizadas por la Ley 19/2013, de 9 de diciembre, de transparencia, acceso a la información pú-

49 Nueva redacción dada al artículo 14.8 de la LO 8/2007, de 4 de julio, por el artículo 1.10 de la LO 3/2015, de 30 de marzo.

50 Circunstancia sobre la que ha llamado la atención el GRECO en reiteradas ocasiones. Cfr. Third Evaluation Round. Second Compliance Report on Spain. "Incriminations (ETS 173 and 191, GPC 2). Transparency of Party Funding», § 30, cit. en nota núm. 32; Third Evaluation Round. Addendum to the Second Compliance Report on Spain. «Incriminations (ETS 173 and 191, GPC 2). Transparency of Party Funding», § 31; cit. en nota núm. 35; y Third Evaluation Round. Second Addendum to the Second Compliance Report on Spain. «Incriminations (ETS 173 and 191, GPC 2). Transparency of Party Funding», § 34, cit. en nota núm. 38. 
blica y buen gobierno (en lo sucesivo Ley 19/2013, de transparencia), los partidos políticos apenas se ven concernidos por las obligaciones de publicidad activa, que comporta que la información «sujeta a las obligaciones de transparencia será publicada en las correspondientes [...] páginas web y de una manera clara, estructurada y entendible para los interesados» (art. 5. 4 de la Ley 19/2013, de transparencia). Aun cuando los partidos políticos figuran expresamente entre los sujetos obligados por las disposiciones contenidas en el Capítulo II del Título I de la Ley 19/2013, de transparencia, relativas a las exigencias de publicidad activa [art. 3 a) $]^{51}$, lo cierto es que toda la información sometida al régimen de transparencia, ya sea de carácter institucional, organizativa y de planificación, de relevancia jurídica, o de tipo económico, presupuestario o estadístico (arts. 6-8 Ley 19/2013, de transparencia), está casi exclusivamente orientada a la actividad desplegada por la Administración y por organismos y entidades de derecho público, pero no por los partidos políticos ${ }^{52}$. Y, además, y sobre todo, pues esta circunstancia es decisiva, los partidos políticos no serán objeto de control por parte del órgano creado por la ley —el Consejo de Transparencia y Buen Gobierno (art. 9. 1 Ley 19/2013, de transparencia) — a fin de velar por el cumplimiento de las obligaciones de publicidad activa contenidas en la propia ley. Y si no hay control, tampoco hay sanción, ya que la Ley de transparencia remite el régimen sancionador para el caso de incumplimiento reiterado de las obligaciones de publicidad activa a la normativa correspondiente reguladora del

51 Sobre el ámbito subjetivo de aplicación de la Ley 19/2013, de transparencia, vid. BARRERO RODRÍGUEZ, M. C., "Transparencia: ámbito subjetivo", Transparencia, Acceso a la Información Pública y Buen Gobierno: estudio de la Ley 19/2013, de 9 de diciembre, Emilio Guichot Reina (coord.), 1 edic., Tecnos, Madrid, 2014, pp. 80-121, en especial, y por lo que se refiere a su aplicación respecto a los partidos políticos, pp. 97-102 (edición electrónica).

52 No obstante, la Ley 19/2013 expresamente recoge la obligación de los partidos políticos de publicar aquellos contratos o convenios que celebren con una Administración Pública, así como aquellas subvenciones que reciban cuando el órgano concedente sea una Administración Pública [art. 8. 2 en conexión con el art. 8. 1 a), b) y c) de la Ley 19/2013, de transparencia]. 
régimen disciplinario de funcionarios públicos o personal de la Administración (art. 9. 2 y 3 Ley 19/2013, de transparencia); o lo que es lo mismo, no prevé sanciones por las posibles infracciones cometidas en este ámbito por los partidos políticos.

Así pues, tal y como se acaba de referir, los partidos políticos escasamente se verán atañidos por las exigencias de publicidad activa contenidas en la Ley de transparencia. Pero, además, los partidos quedan excluidos como posibles sujetos sometidos a las eventuales obligaciones derivadas del ejercicio del derecho legal de acceso a la información pública por los ciudadanos, la otra dimensión de la transparencia que introduce la Ley 19/2013 en el Capítulo III de su Título I. Así las cosas, si materialmente los partidos quedan prácticamente al margen de las exigencias de publicidad activa y, en cualquier caso, excluidos del mecanismo de control y del régimen sancionador con relación a tales exigencias; y formalmente descartados como posibles destinatarios del ejercicio por los ciudadanos del derecho de acceso a la información pública, fácilmente se colegirá que el impacto de la Ley de transparencia sobre los partidos será muy limitado, casi residual.

Si dirigimos ahora nuestra atención a su normativa específica, ésta introduce únicamente algunas, aunque limitadas, obligaciones de publicidad activa para los partidos, por seguir aquí también con las categorías empleadas por la Ley 19/2013, de transparencia. Como ya se ha tenido oportunidad de señalar, la LO 8/2007 había introducido la prohibición general de las donaciones anónimas a los partidos políticos. Sin embargo, esta decisión legislativa, que sin duda representaba un avance notable para contrarrestar la opacidad de las donaciones, no tuvo en cambio efectos equiparables en lo relativo a la transparencia, ya que los partidos políticos no tendrán obligación de publicar todos sus donantes, sino únicamente de identificarlos al Tribunal de Cuentas a efectos de fiscalización; y únicamente tendrán la obligación de publicar, en el plazo de un mes desde la fecha de envío de la contabilidad anual al Tribunal de Cuentas, la identidad de aquellos donantes o legatarios cuando sus donaciones 
o legados sean de un importe superior a 25.000 euros (art. 14. 8 LO 8/2007).

Como igualmente se ha indicado con anterioridad, no es precisamente la transparencia el criterio que rige con relación a las aportaciones obtenidas a través de los convenios de colaboración por las fundaciones y entidades vinculadas a partidos políticos o dependientes de ellos. Como también ya se ha apuntado, la única concesión a la transparencia en este punto viene dada porque estas aportaciones o entregas deberán formalizarse en documento público, comunicarse al Tribunal de Cuentas en el plazo de tres meses desde su aceptación, y «hacerse públicas, preferentemente a través de la página web de la fundación o entidad vinculada» (Disposición adicional 7a 5 LO 8/2007); si bien no se dispone plazo alguno para su efectivo cumplimiento. Además, una vez emitido el informe de fiscalización por el Tribunal de Cuentas, las fundaciones y entidades vinculadas «vendrán obligadas a hacer públicas, preferentemente a través de su página web, el balance y la cuenta de resultados así como las conclusiones del informe de auditoría, de forma que esta información sea de gratuito y fácil acceso para los ciudadanos» (Disposición adicional 7ª 6 LO 8/2007); aunque tampoco aquí se precisa plazo alguno para dar satisfacción a tal obligación.

Y finalmente, según se acaba de apuntar con relación a los créditos concedidos a los partidos políticos, éstos deberán publicar en su página web, en el plazo máximo de un mes desde la fecha de envío de las cuentas anuales al Tribunal de Cuentas, la cuantía de los créditos pendientes de amortización (art. 14. 8 LO 8/2007). Esta exigencia de transparencia, que vale también para las cuentas de los partidos - publicación del balance y de la cuenta de resultados (art. 14. 8 LO 8/2007)—, no se extiende, sin embargo, a los acuerdos de renegociación de las condiciones de la deuda, ya que de tales acuerdos (que en ningún caso podrán comportar condonaciones totales o parciales de deuda) únicamente habrá que informar al Tribunal de Cuentas y al Banco de España (art. 4.4 LO 8/2007), que se convierten así en destinatarios directos y privilegiados de esa información, pero no así los 
ciudadanos que solamente podrían acceder a la misma a través del informe correspondiente de fiscalización anual del Tribunal de Cuentas.

\section{Algunas consideraciones finales}

La regulación legislativa sobre partidos presenta, cuando menos, dos particularidades. En primer lugar, aunque los partidos son asociaciones privadas, ejercen sin embargo funciones públicas, tales como expresar el pluralismo político de la sociedad, ser instrumento fundamental para la participación política, o intermediar entre la sociedad y los órganos del Estado. Y son también los actores principales que intervienen en el proceso electoral, concurriendo de este modo a la formación y manifestación de la voluntad popular, o dicho de otro modo, los partidos protagonizan el proceso a través del cual la sociedad se autodirige políticamente. Por todo ello se erigen en piezas clave para el adecuado funcionamiento del engranaje del Estado democrático. De ahí que el constituyente, excepcionando el poder de autoorganización de las asociaciones, estableciese que su funcionamiento y estructura interna habrían de ser democráticos (art. 6 $\mathrm{CE}$ ). Y de ahí también que su regulación requiera una intensa intervención del legislador que, al abordar los distintos aspectos que conforman el régimen jurídico de los partidos (financiación y transparencia en lo que aquí interesa), habrá de asegurar la libertad, el pluralismo político, la justicia y la igualdad (art. 1. $1 \mathrm{CE}$ ), pues de lo contrario se desvirtuaría ese proceso político - el proceso electoral - a través del cual, como decíamos, la sociedad se autoorganiza o autodetermina políticamente.

Ocurre, sin embargo, y aquí vendría la segunda de las particularidades anunciadas, que cuando el legislador legisla sobre partidos en realidad legisla sobre sí mismo. Son los partidos políticos los que, a través de los grupos parlamentarios en los que se articulan las Cámaras y que ellos ocupan, asumen la condición de legislador; los que en última instancia legislan. Y cuando lo hacen sobre sí mismos se producen dos consecuencias 
a nuestro juicio relevantes a la hora de interpretar y analizar, como se ha procurado hacer en este trabajo, la evolución legislativa en materia de financiación de partidos y transparencia. Una primera, bastante evidente por lo demás, es que, pudiendo evitarlo, nadie propende a la autolimitación o a las autorestricciones, y los partidos políticos tampoco son en esto una excepción. Y la segunda, quizá no tan evidente pero sí igualmente esclarecedora a efectos del análisis realizado, es que cuando los partidos legislan sobre sí mismos no se produce, como sucede normalmente, una confrontación entre posiciones e intereses enfrentados que expresan el pluralismo político de la sociedad y que encarnan respectivamente el partido o partidos que apoyan al gobierno y el partido o partidos de la oposición; sino más bien una confluencia o colusión de intereses entre los partidos mayoritarios o con una fuerte implantación electoral frente a los partidos minoritarios o con limitado respaldo electoral. La primera de las consecuencias descritas explicaría, por ejemplo, que, pudiendo hacerlo, los partidos en cambio no han dispuesto en su propio entramado organizativo eficaces mecanismos de control y fiscalización de la financiación. Y la segunda revelaría, entre otras cosas, la resistencia a introducir modificaciones o a cambiar el sistema electoral. Y ambas explicarían, y en lo que aquí concierne, el mantenimiento en sus rasgos esenciales del modelo de financiación de los partidos, asentado - financiación irregular aparte - en la preponderancia de la financiación pública, cuyos criterios de distribución de los recursos públicos han permanecido estables a lo largo de los años; así como también arrojarían luz respecto, como se ha visto, a las sucesivas modificaciones legislativas introducidas con relación a las fuentes de financiación privada de los partidos y a las nuevas regulaciones en materia de transparencia.

En cuanto a las fuentes privadas de financiación de los partidos es innegable que se han producido notables avances introducidos en las sucesivas reformas legislativas aprobadas hasta el momento. Cierto es que estas reformas, o parte de ellas, se fueron abriendo paso a remolque de una situación de gravísima 
crisis política en la que confluía una profunda crisis económica con el estallido de numerosos casos de corrupción política, muchos de ellos relacionados, directamente o indirectamente, con la financiación irregular de los partidos; cóctel explosivo que provocó un intenso sentimiento de desafección política entre la ciudadanía y que propició en última instancia la voladura de nuestro sistema de partidos, con la aparición de nuevas fuerzas políticas emergentes que quebraban así la relativa estabilidad de nuestro modelo de partidos; estabilidad, por cierto, que también facilitaba el sistema de financiación de partidos. Y tampoco se puede ignorar que, aun cuando seguramente en menor medida, a tales reformas no fueron ajenas tampoco, como se ha visto en las páginas que preceden, las recomendaciones de organismos internacionales, señaladamente las efectuadas por el GRECO, organismo perteneciente al Consejo de Europa.

Y tan cierto como lo uno y lo otro, lo es también que esos avances se produjeron y acabaron por incorporarse a las sucesivas reformas aprobadas a tal efecto por el legislador. En este sentido no son despreciables las mejoras introducidas en materia de donaciones privadas a los partidos: desde la prohibición de las donaciones anónimas hasta la exclusión de las personas jurídicas y de los entes sin personalidad jurídica de la condición de potenciales donantes, pasando por la reducción de la cuantía máxima anual permitida por donante y partido a 50.000 euros (si bien se excepciona de este límite las donaciones de bienes inmuebles), o la mejora del sistema de fiscalización y del régimen sancionador. Y tampoco son desdeñables las modificaciones que el legislador ha introducido con relación a los acuerdos de renegociación de las deudas crediticias contraídas por los partidos políticos con las entidades financieras. En realidad, estos acuerdos, que comportaban frecuentemente condonaciones totales o parciales de la deuda, no hacían más que esconder ingentes donaciones encubiertas. Y hasta podría vislumbrarse un reconocimiento tácito o implícito por parte del legislador de esta circunstancia, pues sometió a las condonaciones de deuda a los mismos límites que iba estableciendo paulatinamente para las 
donaciones privadas: primero limitándolas, igual que las donaciones, a una cuantía máxima de 100.000 euros anuales, y luego prohibiéndolas al mismo tiempo que se prohibían las donaciones realizadas por personas jurídicas. Claro que al no regularse los términos y condiciones de los préstamos y no establecerse un límite de endeudamiento, se allana el camino hacia el sobreendeudamiento de los partidos y su consiguiente mayor exposición y vulnerabilidad respecto a los bancos.

Pero es sobre todo con relación a las aportaciones a las fundaciones y entidades vinculadas a los partidos donde se plasma con mayor claridad ese, si se me permite la expresión, juego al solitario del legislador al que nos venimos refiriendo, consistente en que, al mismo tiempo que cierra o limita unas vías o fuentes de financiación, abre otras de par en par. Éste es el caso de las donaciones efectuadas a estas fundaciones o asociaciones vinculadas a los partidos. Mientras, como hemos visto, se suprimían las donaciones de personas jurídicas en favor de los partidos, no sólo se admitían cuando el beneficiario de las mismas fuesen fundaciones o entidades vinculadas, sino que además no se impide que tales liberalidades procedan de empresas privadas con contratos en vigor con la Administración. De igual modo, al mismo tiempo que se reducían las cuantías máximas anuales de las donaciones privadas a los partidos, no sólo no se rebajaban esas cuantías máximas, sino que se suprimía cualquier límite a la cuantía de las donaciones efectuadas en favor de las fundaciones y entidades vinculadas. Y, sobre todo, será a través de los convenios de colaboración y la opacidad que los envuelve por donde se abra una vía de financiación, un régimen de auténtica barra libre a disposición de los partidos para ser utilizado como un instrumento indirecto de financiación. Tanto es así que el propio Tribunal de Cuentas advirtió reiteradamente que tras las aportaciones efectuadas al amparo de estos convenios de colaboración se camuflaban donaciones encubiertas. Pero en este caso, el legislador, consciente probablemente de que no puede cegar todas las vías de financiación de los partidos y de ese modo impedirles hacer frente a sus ingentes gastos, lejos de seguir el criterio del 
Tribunal de Cuentas, expresamente estableció que tales aportaciones en ningún caso tendrían la consideración de donaciones. Y de ello además se seguía una consecuencia ulterior en modo alguno baladí, ya que tales aportaciones, al no tener la consideración de donaciones, podrían provenir no sólo de personas jurídico-privadas, sino también de personas jurídico-públicas.

Tal vez todo este devenir legislativo en materia de financiación de partidos viene a confirmar la sospecha de que cualquier política legislativa encaminada a procurar sellar las posibles vías de financiación indirecta, así como también las de financiación irregular, y de este modo, si no impedir completamente, sí al menos dificultar la corrupción política ligada a la financiación irregular de los partidos, estará condenada irremisiblemente a no alcanzar sus objetivos, si simultáneamente no se complementa con una política orientada a limitar los gastos de los partidos, en particular los electorales ${ }^{53}$. Si únicamente se pone el foco en las fuentes de financiación, el legislador-legislado - los partidos políticos - seguramente hallará el modo, como se ha visto, de habilitar alguna o algunas de esas posibles vías de financiación como vías de acceso al formidable caudal de financiación que los partidos precisan para sufragar sus gastos, $\mathrm{y} / \mathrm{o}$, a tal fin, esos mismos partidos podrían intentar recurrir a mecanismos de financiación irregular.

Los partidos, por último, no se han visto demasiado expuestos a las obligaciones de transparencia. La Ley 19/2013, de transparencia, aunque acabó por incluirlos en la serie de sujetos obligados, optó en cambio por su aplicación parcial. Opción ésta, por cierto, que fue acordada — tal vez no por casualidad y sí en cambio de forma muy significativa - por los dos grandes grupos parlamentarios — los del PP y el PSOE - en la fase de tramitación de la $l y^{54}$. Por este motivo la Ley de transparen-

53 BLANCO VALDÉS, "La caída de los dioses: de los problemas de los partidos a los partidos como problemas", p. 170, cit. en nota núm. 10.

54 BARRERO RODRÍGUEZ, “Transparencia: ámbito subjetivo”, p. 98, cit. en nota núm. 51. 
cia los exime de las obligaciones de publicidad pasiva, esto es, de las obligaciones derivadas del ejercicio del derecho legal de acceso a la información pública por los ciudadanos. Y aunque formalmente los incluye entre los sujetos obligados por las exigencias de publicidad activa, materialmente los excluye y, en cualquier caso, los deja al margen del sistema de control y fiscalización y del régimen sancionador.

Claro que, si acudimos a su normativa específica, comprobaremos que en ella nada hay que se refiera a las obligaciones de los partidos nacidas del ejercicio por los ciudadanos del derecho de acceso a la información pública. Quedan, pues, excluidos de las exigencias de publicidad pasiva. Y por lo que se refiere a las de publicidad activa, salvo en el caso de la publicación de las cuentas y de los créditos pendientes de amortización (pero no, en cambio, de los acuerdos de renegociación de las condiciones de la deuda), que deberá hacerse en las webs respectivas en el plazo de un mes desde el envío de la contabilidad anual al Tribunal de Cuentas, en lo demás estas obligaciones son muy limitadas y de efecto reducido. Como se recordará, los partidos únicamente se verán obligados a publicar aquellas donaciones que tengan un importe superior a 25.000 euros; $y$ en lo que atañe a las fundaciones vinculadas deberán publicar, preferentemente en sus páginas web, las aportaciones recibidas a través de los convenios de colaboración, así como su contabilidad y el correspondiente informe de auditoría, si bien sin sujeción a plazo alguno en ambos casos y, en el segundo, previo informe de fiscalización del Tribunal de Cuentas, de modo que, en este último caso, de llevarse a cabo tal publicación, previsiblemente sería extemporánea $\mathrm{y}$, en consecuencia, de escasa utilidad.

\section{Bibliografía}

BARRERO RODRÍGUEZ, María Concepción (2014). “Transparencia: ámbito subjetivo", en Emilio Guichot Reina, Transparencia, Acceso a la Información Pública y Buen 
Gobierno: estudio de la Ley 19/2013, de 9 de diciembre. Madrid: Tecnos, (edición electrónica).

BLANCO VALDÉS, Roberto L. (2015). "La caída de los dioses: de los problemas de los partidos a los partidos como problemas." Teoría y Realidad Constitucional, núm. 35: 149-182.

DELGADO DEL RINCÓN, Luis Esteban (2016). “El control económico-financiero de los partidos políticos por el Tribunal de Cuentas: su potestad sancionadora." Revista de derecho político, núm. 97: 49-88.

KELSEN, Hans (1934). Esencia y valor de la democracia, trad. Rafael Luengo Tapia y Luis Legaz y Lacambra, Barcelona-Buenos Aires: Labor.

KATZ, Richard S., y MAIR, Peter (2004). "El partido cartel: La transformación de los modelos de partidos y de la democracia de partidos." Zona abierta, núm. 108-109: 9-42.

MARTÍN CAVANNA, Javier (2015). Los 10 mayores errores sobre transparencia, supervisión y buen gobierno 20142015. Madrid: Fundación Compromiso y Transparencia, disponible en http://ifuturo.org/documentacion/Los10mayoreserroressobretransparencia.pdf, [último acceso: 2017].

PAJARES MONTOLÍO, Emilio J (1998). La financiación de las elecciones. 1. ${ }^{\mathrm{a}}$ ed. Madrid: Congreso de los Diputados.

PASQUINO, Gianfranco (1982). "Contro il finaziamento pubblico di questi partiti", en Degenerazioni dei partiti e riforme istituzionali. Roma: Laterza.

PUENTE ABA, Luz María (2017). El delito de financiación ilegal de partidos políticos. Valencia: Tirant lo Blanch.

RUIZ-RICO RUIZ, Gerardo José (2015). "El control sobre la financiación de los partidos políticos: un desafío permanente para el legislador." Teoría y Realidad Constitucional, núm. 35: 281-308.

_ (2011), "El derecho a una buena administración. Dimensiones constitucional y estatutaria", en Carmen María Ávila Rodríguez y Francisco J. Gutiérrez Rodríguez, El 
derecho a una buena administración y la ética pública. Valencia: Tirant lo Blanch.

SÁNCHEZ MUÑOZ, Óscar (2015). "La insuficiente reforma de la financiación de los partidos: la necesidad de un cambio de modelo". Revista española de derecho constitucional, vol. 35, núm. 104: 49-82.

\section{Documentos}

«Informe de fiscalización de los estados contables de los partidos políticos y de las donaciones percibidas por las fundaciones vinculadas orgánicamente, ejercicio 2007», BOE, 5 de marzo de 2013, núm. 55.

«Informe de fiscalización de los estados contables de los partidos políticos y de las donaciones percibidas por las fundaciones vinculadas orgánicamente, ejercicio 2008», BOE, 11 de febrero de 2014, núm. 36.

«Informe de fiscalización de los estados contables de los partidos políticos y de las donaciones percibidas por las fundaciones vinculadas orgánicamente, ejercicios 2009, 2010 y 2011», BOE, 12 de mayo de 2014, núm. 115.

«Informe de fiscalización de los estados contables de los partidos políticos y de las aportaciones percibidas por las fundaciones y asociaciones vinculadas orgánicamente, ejercicio 2013», BOE, 7 de abril de 2017, núm. 83.

«Informe de la Subcomisión relativa al régimen y la financiación de los partidos políticos», BOCG, 22 de marzo de 2018, núm. 323.

Tercera Ronda de Evaluación. «Informe de Evaluación sobre Transparencia en la Financiación de Partidos Políticos en España», (28 de mayo de 2009), disponible en https:// rm.coe.int/16806c9d70, [último acceso: 2017].

Third Evaluation Round. Compliance Report on Spain. "Incriminations (ETS 173 and 191, GPC 2). Transparency of Party Funding», (12 de abril de 2011), disponible en https://rm.coe.int/16806c9daf, [último acceso: 2017]. 
Third Evaluation Round. Second Compliance Report on Spain. «Incriminations (ETS 173 and 191, GPC 2). Transparency of Party Funding», (11 de julio de 2013), disponible en https://rm.coe.int/16806c9db2 [último acceso: 2017].

Third Evaluation Round. Addendum to the Second Compliance Report on Spain. "Incriminations (ETS 173 and 191, GPC 2). Transparency of Party Funding», (3 de marzo de 2015), disponible en https://rm.coe.int/16806c9db6 [último acceso: 2017].

Third Evaluation Round. Second Addendum to the Second Compliance Report on Spain. "Incriminations (ETS 173 and 191, GPC 2). Transparency of Party Funding》, (9 de febrero de 2016), disponible en https://rm.coe. int/16806cac21 [último acceso: 2017]. 